\title{
Manual de los Reglamentos del Agua en Florida: Poderes Reguladores del Estado ${ }^{1}$
}

Michael T. Olexa, Luke D'Isernia, Laura Minton, Dulcy Miller y Sara Corbett ${ }^{2}$

\section{Prefacio}

Este manual esta diseñado para proporcionar un resúmen autorizado, exacto y actual de las principales leyes Federales y de Florida que están directa o indirectamente relacionadas a la agricultura. Este manual debe proveer una vista general de los muchos derechos y responsabilidades que tienen los agricultores y propietarios de tierras agrícolas bajo las leyes tanto Federal como de Florida, así como también la información de los contactos apropiados para obtenerla con más detalle. Sin embargo, el lector debe estar advertido de que algunas partes de esta publicación podrían volverse obsoletas en cualquier momento, debido a que las leyes, reglas administrativas, y decisiones de la corte, sobre las cuales se basa este manual, se encuentran bajo revisión constante. Algunos detalles de las leyes citadas no se mencionan, debido a limitaciones de espacio.

Este manual es distribuido con la aclaración de que los autores no intentan proporcionar una asesoría legal o profesional, y que la información contenida aquí no debe ser considerada como un sustituto de asesoría profesional. En este manual, no se incluye toda la información para llevar a cabo el cumplimiento de las leyes Federales y de Florida y los reglamentos que rigen la protección del agua. Por estas razones, el uso de estos materiales por cualquier persona, constituyen un acuerdo para mantener libre de perjuicios a los autores, al Servicio de Extensión Cooperativa de Florida, al Instituto de los Alimentos y Ciencias Agrícolas y a la Universidad de Florida por reclamos de responsabilidad, daños o gastos provenientes de quien sea, por haberse referido o basado en la información contenida en este manual.

\section{Vista General de la Ley del Estado}

La ley del Estado llena los vacíos y complementa la ley federal, y frecuentemente la duplica. Sin embargo, en muchos casos los estándares de la ley estatal son más estrictos que los de la ley federal. Consecuentemente cumplir con

1. Este es el documento EDIS FE064, una publicación de Food and Resource Economics Department, Florida Cooperative Extension Service, Institute of Food and Agricultural Sciences, University of Florida, Gainesville, FL. Publicado Noviembre 2006. Por favor visite la página electrónica de EDIS en http://edis.ifas.ufl.edu.

2. Michael T. Olexa, profesor, Food and Resource Economics Department y director, Agricultural Law Center, University of Florida, Gainesville, FL, y presidente, Agricultural Law Committee, The Florida Bar; Luke D'Isernia, alumni, Levin College of Law, University of Florida, Gainesville, FL; Laura Minton, abogado, Dean, Mead, Egerton, Bloodworth, Capouano y Bozarth, PA, Orlando FL; Dulcy Miller, abogado, Foley and Lardner, LLP, Orlando, FL; y Sarah Corbett, abogado, Florida Second District Court of Appeal, Lakeland, FL. La traducción del ingles al español estuvo a cargo de Filiberto Reyes-Villanueva.

EI Instituto de Alimentos y Ciencias Agrícolas es un empleador que opera bajo Acción Afirmativa y provee Oportunidades Igualitarias, autorizado a proveer investigación, información educativa y otros servicios, únicamente a los individuos e instituciones que operan sin discriminación alguna con relación al credo, color, religión, edad, incapacidad, sexo, orientación sexual, estado civil, nacionalidad, opinion política o afiliaciones. Para más información sobre como obtener otras publicaciones de extensión, comuníquese con la oficina de Servicio de Extensión de su condado. Servicio de Extensión de la Florida / Instituto de Alimentos y Ciencias Agrícolas / Universidad de la Florida / Larry Arrington, Decano. 
la ley estatal a menudo asegura cumplir también con la federal. En dos palabras, la ley del estado toma dos formas: estatutos y reglas administrativas.

\section{Estatutos}

Los estatutos son aprobados por la legislatura del estado y son los medios para alcanzar las metas básicas de la legislatura, y los procedimientos que ella quiere aplicar para lograrlas. Aunque los estatutos frecuentemente proporcionan indicaciones y prohibiciones específicas, muchos detalles de la reglamentación en un área de negocios o en un aspecto ambiental, a menudo son demasiado técnicos y minuciosos como para que la legislatura los trate.

\section{Reglas Administrativas}

La legislatura generalmente se basará en agencias administrativas para alcanzar sus metas específicas. Para hacer esto, la legislatura otorga poderes a las agencias administrativas para adoptar reglas (las cuales tienen la fuerza de una ley) dentro de los límites estrechos aprobados por la legislatura.

Por ejemplo, si la legislatura decidió que hubo un interés del estado para regular el uso de ciertos plaguicidas, puede aprobar un estatuto que defina ampliamente los usos o prohibiciones de plaguicidas, y le permite a una agencia (es este caso el Departamento de Agricultura y Servicios del Consumidor) reglamentar acerca de cuándo, por quién, y en qué cantidades debe ser aplicado el plaguicida. En la mayoría de los casos, las agencias también tienen el poder para hacer cumplir sus reglas a través de condenas penales y civiles, así como también con reglamentos de permisos/licencias.

\section{¿Cómo Están Restringidas las Acciones del Gobierno y del Estado?}

Para asegurar que las agencias actúen justamente con aquellos quienes están sujetos a su regulación, Florida ha aprobado las siguientes leyes:

- Acta del Procedimiento Administrativo de Florida (Capitulo 120, de los Estatutos de Florida-estatuto establece el mecanismo clave para permitir la entrada de información privada en las acciones y reglamentaciones de la agencia). Esta Acta establece muchos derechos de procedimiento como los siguientes:

1. El derecho a ser escuchado por la agencia.

2. El derecho a recibir noticias de acciones de la agencia.

3. Una oportunidad de garantía para aquellos quienes son más afectados para usar esos derechos.

- La Ley de los Registros Públicos de Florida (o Capitulo 119, de los Estatutos de Florida). Este estatuto estipula que todos los registros de la agencia, con pocas excepciones reglamentarias, están disponibles al publico para inspección y copiado. Las excepciones se encuentran donde la confidencialidad de información es necesaria para la eficiencia administrativa de gobierno o donde la divulgación podría afectaría adversamente el cumplimiento de la ley.

- Ley del Sol Brillante de Florida (Capitulo 286, de los Estatutos de Florida) declara que todas las reuniones de cualquier cuerpo gubernamental donde es tomada alguna acción oficial, debe estar abierta al publico y las minutas (acuerdos escritos) deben ser registrados. Este estatuto no es una garantía incondicional de acceso al gobierno, porque en realidad queda un largo camino para que los cuerpos administrativos estén accesibles al público.

\section{¿Cómo Es la Estructura de las Agencias de Florida?}

La mayoría de las agencias estatales tienen estructuras similares. Muchas mantienen sus oficinas centrales en Tallahassee y tienen oficinas regionales por todo el estado. Dentro de cada agencia, puede haber varias divisiones, cada una con sus propios deberes asignados (ej., otorgar y hacer cumplir permisos, e información pública). Muchas agencias están encabezadas por un secretario, quien se mantiene en contacto directo con el gobernador. Otras agencias están dirigidas por un oficial del gabinete $\mathrm{o}$ un comisionado contratado. Todos se mantienen en contacto directo con la legislatura para mantenerse al 
día de los cambios de política y mantener las reglas actualizadas.

La estructura de gobiernos de ciudades y condados, varía de gobierno a gobierno, pero cada una tiene sus propias divisiones desde las pequeñas áreas rurales hasta las populosas áreas urbanas. Cada condado y ciudad esta encabezada por una comisión electa. Algunos dependen de jefes profesionales para dirigir los aspectos cotidianos del gobierno, mientras otros dependen de funcionarios electos.

\section{Agradecimientos}

Los autores agradecen al personal de las agencias estatales y federales por su tiempo y asesoría en la preparación de este manual. Los autores agradecen especialmente a Richard Budell del Office of Agricultural Water Policy of the Florida Department of Agriculture and Consumer Services por el apoyo económico para el desarrollo de esta publicación. 